\title{
Christella normalis (C. Chr.) Holttum (Thelypteridaceae), nueva especie alóctona y naturalizada para la provincia de Sevilla (Andalucía, España)
}

\author{
Juan José Ranchal Muñoz ${ }^{1}$, Juan Antonio Figueras Martínez², Sixto Miguel Montero Ruiz ${ }^{3}$ y Javier \\ López-Tirado ${ }^{4}$ \\ ${ }^{1} \mathrm{c} /$ Julio Romero de Torres, 4, CP 41870, Aznalcóllar (Sevilla) \\ ${ }^{2} \mathrm{c} /$ Industria, 8, CP 41870, Aznalcóllar (Sevilla) \\ ${ }^{3} \mathrm{c} /$ Sánchez Becerra, 8, urbanización La Torre, 14, CP 41870 Aznalcóllar (Sevilla) \\ ${ }^{4}$ Departamento de Botánica, Ecología y Fisiología Vegetal, Edificio Celestino Mutis, Campus de Rabanales, Universidad de \\ Córdoba, 14071 Córdoba (España).
}

\section{Correspondencia}

Javier López Tirado

E-mail: javier.lopez.tirado@uco.es

Recibido: 1 julio 2021

Aceptado: 14 julio 2021

Publicado on-line: 22 julio 2021

Editado por: Marta Recio Criado

\begin{abstract}
Resumen
Se cita por primera vez el pteridófito alóctono y naturalizado Christella normalis (C. Chr.) Holttum (Thelypteridaceae) para la provincia de Sevilla.
\end{abstract}

Palabras clave: Corología, Thelypteridaceae, Christella normalis, novedad, Sevilla.

\begin{abstract}
Christella normalis (C. Chr.) Holttum (Thelypteridaceae), new alien and naturalized record for Seville province (Andalusia, Spain)

The alien and naturalized pteridophyte Christella normalis (C. Chr.) Holttum (Thelypteridaceae) is recorded for the first time in Seville province.
\end{abstract}

Key words: Chorology, Thelypteridaceae, Christella normalis, new record, Seville.
Christella normalis (C. Chr.) Holttum es un pteridófito nativo del continente americano (Smith, 1993). Esta especie se ha encontrado en los últimos años naturalizada en el continente europeo, concretamente en España, de donde se conocen poblaciones en Córdoba [sub. Thelypteris kunthii (Desv.) C.V. Morton] y Comunidad Valenciana (Girard \& Vivant, 1995; López-Tirado, 2017; Fabado et al., 2020). Recientemente se ha detectado una población con ejemplares fértiles de gran tamaño en la provincia de Sevilla (Figura 1), lo que supone novedad corológica para la misma y amplía su distribución en Andalucía occidental. Se ha depositado un pliego testigo en el Herbario de la Facultad de Ciencias de la Universidad de Córdoba (COFC).

Christella normalis (C. Chr.) Holttum

SEVILLA. Aznalcóllar: Arroyo de los Arquillos, canal del PAMA [29SQB4355], 75 m, 11.VI.2021 (COFC 72177). Leg.: Juan José Ranchal Muñoz, Juan Antonio Figueras Martínez \& Sixto Miguel Montero Ruiz. Det.: Javier López Tirado.

En su área nativa se considera una especie capaz de colonizar cunetas de carreteras, por tanto, comportándose como viaria, y otros ecosistemas con cierto grado de humedad o encharcamiento (Smith, 1971). Christella normalis es una especie usada como ornamental, que puede escaparse de poblaciones de jardinería y naturalizarse si encuentra el hábitat apropiado. Además de su reproducción sexual en la nueva localidad, se suma su reproducción asexual por medio de división del rizoma. Al igual que en Córdoba, esta especie se cultiva en los patios y casas de Aznalcóllar, probable

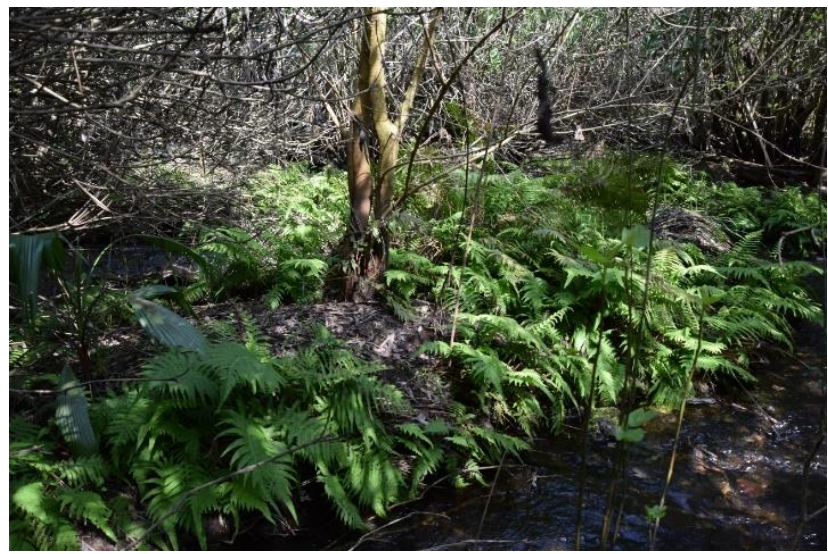

Figura 1. Christella normalis en la nueva población hallada en Aznalcóllar (Sevilla).

Figure 1. Christella normalis in the new locality from Aznalcóllar (Seville).

origen de la naturalización de este helecho en el Arroyo de los Arquillos. Se estima que la nueva población consta de unos 200 ejemplares diseminados en unos $1500 \mathrm{~m}^{2}$, con frondes de 90 a $120 \mathrm{~cm}$ de longitud. Se comporta como especie riparia, creciendo tanto en pequeñas islas en el cauce 
del arroyo como en la ribera, y se acompaña de especies típicas de estos ambientes tales como la adelfa (Nerium oleander L.), la zarza (Rubus ulmifolius Schott), la higuera (Ficus carica L.), la arroyuela (Lythrum salicaria L.) o la rosa (Rosa canina L.), entre otras. Futuros seguimientos podrán arrojar luz sobre la dinámica de esta población con vistas a valorar si tiene comportamiento invasor.

\section{BIBLIOGRAFÍA}

Fabado, J., J. Riera, G. Ros, C. Fabregat, C. Mir \& E. Laguna (2020). Consideraciones sobre la familia Thelypteridaceae Ching ex Pic. Serm. en la Comunidad Valenciana. Flora Montiberica 77, 65-69.

Girard, C. \& J. Vivant (1995). À propos de deux fougères adventices en Europe: Cyrtomium fortunei J. Smith et Thelypteris kunthii (Desv.) Morton. Le Monde des Plantes 454, 20-21.

López-Tirado, J. (2017). First record of the american native fern Thelypteris kunthii (Desv.) C.V. Morton from Europe. American Fern Journal 106(4), 269270.

Smith, A. R. (1971). Systematics of the neotropical species of Thelypteris section Cyclosorus. University of California publications in Botany. Vol. 59, 143 pp.

Smith, A. R. (1993+). Thelypteris Schmidel. In, Flora of North America Editorial Committee, eds. Flora of North America North of Mexico [Online]. 21+ vols. New York and Oxford. Vol. 2.

http://beta.floranorthamerica.org/Thelypteris. [Último acceso en junio de 2021]. 